\title{
Prevalence, antimicrobial susceptibility pattern, and associated factors of Salmonella and Shigella among food handlers in Adigrat University student's cafeteria, northern Ethiopia, 2018
}

Haftom Legese ${ }^{1 *} \mathbb{D}$, Tsega Kahsay ${ }^{1}$, Aderajew Gebrewahd ${ }^{1}$, Brhane Berhe ${ }^{1}$, Berhane Fseha², Senait Tadesse ${ }^{3}$, Guesh Gebremariam', Hadush Negash', Fitsum Mardu', Kebede Tesfay' and Gebre Adhanom

\begin{abstract}
Background: Food handlers play a significant role in the transmission of foodborne infections. Salmonella and Shigella are the most common foodborne pathogens and their infections are a major public health problem globally. Thus, this study aimed to determine the prevalence, antimicrobial susceptibility patterns, and associated factors of Salmonella and Shigella colonization among food handlers.

Methodology: A cross-sectional study was conducted from March to August 2018 at Adigrat University student cafeteria, Northern Ethiopia. Data on socio-demographic and associated factors were collected using a structured questionnaire. Fresh stool samples were collected from 301 food handlers and transported to Adigrat University Microbiology Laboratory. Bacterial isolation and antimicrobial susceptibility test were performed using standard bacteriological methods. Data analysis was performed using SPSS version 22 and $P<0.05$ where a corresponding 95\% confidence interval was considered statistically significant.

Results: A total of 301 food handlers were included in this study. The majority of study participants were females 265 (88.0\%). About 22 (7.3\%) and 11 (3.7\%) of food handlers were found to be positive for Salmonella and Shigella respectively. Hand washing after using a bathroom with water only, no hand washing after using the bathroom, no hand washing after touching dirty materials, no hand washing before food handling, and untrimmed fingernails were significant associated factors identified. None of the Salmonella and Shigella isolates were sensitive to ampicillin, yet low resistance against chloramphenicol, ceftriaxone, and ciprofloxacin was found.

Conclusion: The present study revealed that the prevalence of Salmonella and Shigella among food handlers was $22(7.3 \%)$ and 11 (3.7\%) respectively. Such colonized food handlers can contaminate food, and drinks and could serve as a source of infection to consumers. This indicates that there is a need for strengthened infection control measures to prevent Salmonella and Shigella transmission in the students' cafeteria.
\end{abstract}

Keywords: Antimicrobial susceptibility, Food handlers, Salmonella, Shigella, Ethiopia

\footnotetext{
* Correspondence: legesehaftom2@gmail.com

'Department of Medical Laboratory, College of Medicine and Health Science, Adigrat University, Adigrat, Ethiopia

Full list of author information is available at the end of the article
}

\section{$\triangle B M C$}

(c) The Author(s). 2020 Open Access This article is licensed under a Creative Commons Attribution 4.0 International License, which permits use, sharing, adaptation, distribution and reproduction in any medium or format, as long as you give appropriate credit to the original author(s) and the source, provide a link to the Creative Commons licence, and indicate if changes were made. The images or other third party material in this article are included in the article's Creative Commons licence, unless indicated otherwise in a credit line to the material. If material is not included in the article's Creative Commons licence and your intended use is not permitted by statutory regulation or exceeds the permitted use, you will need to obtain permission directly from the copyright holder. To view a copy of this licence, visit http://creativecommons.org/licenses/by/4.0/ The Creative Commons Public Domain Dedication waiver (http://creativecommons.org/publicdomain/zero/1.0/) applies to the data made available in this article, unless otherwise stated in a credit line to the data. 


\section{Background}

Foodborne diseases are a major public health problem globally. The severity is higher among developing countries due to low hygienic food handling practices, lack of environmental sanitation, and poor access to safe drinking water [1]. In developing countries, approximately $70 \%$ of cases of diarrheal diseases are associated with the consumption of contaminated food [2].

Salmonella remains a major cause of foodborne infection in humans [3], which leads to approximately 93 million infections every year $[4,5]$. The World Health Organization (WHO) estimates that there are around 16 million new cases and 600,000 deaths due to typhoid fever each year worldwide [6]. It causes bacterial bloodstream infections with a fatality rate of $20-25 \%$ [7]. The widespread nature of salmonellosis increases antibiotic resistance which in turn increases the treatment cost, hospitalization, morbidity, and mortality [8].

These bacteria are transmitted directly and indirectly through contaminated objects such as food, water, nails, and fingers. This indicates those microorganisms can be spread by fecal-oral human-to-human transmission [ 9 , 10]. Compared to other parts of the hand, fingernails harbor the most microorganisms and are difficult to clean.

Shigella continues to play a major role in the etiology of inflammatory diarrhea and dysentery in food handlers [11]. The annual incidence of Shigella is estimated to be 164.7 million people, with $69 \%$ of all deaths attributable to shigellosis worldwide $[12,13]$. The highest prevalence of shigellosis is observed in tropical and subtropical parts of the world [14].

Salmonella and Shigella are a significant cause of severe post-diarrheal complications such as reactive arthritis, sepsis, Reiter's syndrome, myocarditis, inflammatory bowel diseases, irritable bowel syndrome, and peritonitis $[8,15,16]$. The emergence of antimicrobial-resistant Salmonella and Shigella becomes a significant threat to deliver reliable therapies $[17,18]$.

In Ethiopia, it is difficult to estimate the severity of salmonellosis and shigellosis as well as their antibiotic resistance due to the limited scope of studies, lack of coordinated epidemiological surveillance system, poor reporting system, and limited availability of culture facilities [19].

Determining the prevalence and antimicrobial susceptibility pattern of Salmonella and Shigella is very important for the proper selection of antimicrobial agents to control the spread of infection. However, in the study area, there was a scarcity of data on the carriage of Salmonella and Shigella among food handlers. Therefore, this study aims to assess the prevalence, antimicrobial susceptibility patterns, and associated factors of Salmonella and Shigella among food handlers in Adigrat University, Tigrai, Northern Ethiopia.

\section{Materials and methods}

\section{Study design, area and period}

A cross-sectional study was conducted among food handlers who participated in food preparation, dispatch and storage at the Adigrat University student cafeteria from March to August 2018. The annual rainfall ranges from 400 to $600 \mathrm{~mm}$ and the minimum and maximum temperature range from 6 to $21.8^{\circ} \mathrm{C}$. Currently, the university enrolls more than 15,000 students dining in the student cafeteria. There are six cafeterias, and a total of 700 food handlers are working in the student cafeteria (Adigrat University human resource management and registrar office). Few food handlers in the university received food handling certification and graduated in food handling, preparation, and serving programs. Although there was a periodic medical checkup in the university, it was not consistent. In contrast to the university food handlers, food handlers employed in serving the public and tourists are well-trained and graduate in food preparation and handling practice from college or universities.

\section{Sample size determination and sampling technique Sample size determination}

The sample size was determined by using a single population proportion formula.

$$
\mathrm{n}=\frac{(\mathrm{Z} \alpha / 2)^{2} \mathrm{P}(1-\mathrm{P})}{\mathrm{d}^{2}}
$$

The sample size was determined based on the prevalence of Salmonella among university food handlers done by Mama and Alemu (2016) at Arba Minch University, South Ethiopia (6.9\%) [14]. Then with a margin of error $(5 \%),(d=0.03)$ and $95 \%$ level of confidence $(z=$ 1.96), the sample size was calculated as follows:

$$
\begin{aligned}
\mathrm{n} & =\frac{(1.96)^{2} * 0.069(0.931)}{(0.03)^{2}} \\
& =274, \text { with } 10 \% \text { non response rate }=301
\end{aligned}
$$

Therefore, a total of 301 food handlers were included in the study from all university cafeterias. A simple random sampling technique was employed. The lottery method was used to select the study subjects after a complete list of food handlers was obtained from a roster of cafeteria staff at Adigrat University.

\section{Eligibility criteria \\ Inclusion criteria}

Food handlers working in Adigrat University student cafeterias were included in the study. 


\section{Exclusion criteria}

Food handlers who have taken antibiotics and/or antihelminthics within one week and those with clinical signs of typhoid fever such as cough, a high temperature which reaches up to 39 to $40 \mathrm{C}$, headache, general aches and pains were excluded from the study.

\section{Data collection and sample processing}

Socio-demographic and specimen collection, handling and transportation

A structured questionnaire was used to collect the data regarding socio-demographic and associated factors. Questionnaires were checked for accuracy and completeness. After proper instruction, about $2 \mathrm{~g}$ of fresh stool specimens were collected from food handlers with a labeled wide-mouthed plastic container and a clean wooden applicator stick. Specimens were immediately transported to the laboratory using an icebox.

\section{Isolation and identification}

The stool specimen was collected and transported to Adigrat University Medical Microbiology Laboratory within one hour of collection. Stool specimens were immediately inoculated in Selenite F enrichment broth and incubated at $37^{\circ} \mathrm{C}$ for $24 \mathrm{~h}$, and then subculture onto selective media of xylose-lysine desoxycholate agar (XLD) and Hektoen enteric medium agar at $37^{\circ} \mathrm{C}$ for $18-24 \mathrm{~h}$. The isolated colonies were differentiated and identified based on Gram stain, colonial morphology and pigmentation, hemolysis on blood agar, catalase test, oxidase test, carbohydrate fermentation, $\mathrm{H}_{2} \mathrm{~S}$ production, motility, indole formation, urease production, and citrate utilization. Cultures were incubated for 24 to $48 \mathrm{~h}$ at $37^{\circ} \mathrm{C}$. Then colonies producing an alkaline slant with acid butt and hydrogen sulfide production on Triple Sugar Iron Agar, positive for lysine, negative for urea hydrolysis, negative for indole test, positive for citrate utilization and motility test were considered to be Salmonella. Colonies which were urease negative, indole positive/negative, produced a pink-red slope and yellow butt with no blackening on Triple Sugar Iron agar, lysine decarboxylase negative and citrate negative were identified as Shigella species. Finally, all of the confirmed Salmonella and Shigella isolates were examined for antimicrobial susceptibility.

\section{Antimicrobial susceptibility tests}

Antimicrobial susceptibility testing was performed using the modified Kirby-Bauer disc diffusion method according to Clinical and Laboratory Standards Institute (CLSI) guidelines, 2016 [20]. Using a sterile wire loop, 3-5 wellisolated colonies of the test organism was emulsified into a tube of 3-4 ml sterile physiological saline to get bacterial inoculums equivalent to $0.5 \mathrm{McF}$ arland turbidity standards. Then the standardized suspension (test organisms) were uniformly swabbed within $15 \mathrm{~min}$ using a sterile cotton swab into Muller-Hinton agar and allowed to dry. After that, the antibiotic discs were placed manually on the medium and incubated at $37^{\circ} \mathrm{C}$ for about 18 $h$ and the zones of inhibition were measured using a caliper. The interpretation of the results was made based on the CLSI criteria as sensitive, intermediate and resistant [20]. The following antimicrobials were prioritized by considering local prescription; gentamicin $(10 \mu \mathrm{g})$, ampicillin $(30 \mu \mathrm{g})$, amoxicillin $(30 \mu \mathrm{g})$, ciprofloxacin $(5 \mu \mathrm{g})$, clarithromycin $(30 \mu \mathrm{g})$, chloramphenicol $(30 \mu \mathrm{g})$, cotrimoxazole $(25 \mu \mathrm{g})$, amoxicillin-clavulanic acid $(30 \mu \mathrm{g})$, and ceftriaxone $(30 \mu \mathrm{g})[20]$.

\section{Data quality assurance}

Data quality was ensured at various activities of the study by following a prepared standard operating procedure (SOP). Questionnaires were prepared in a clear and precise way and translated into the local language and back-translated to English to ensure the consistency of the questionnaires. The pretest was done on $5 \%$ of food handlers and modifications were made accordingly. To ensure general safety, universal bio-safety precautions were followed. American Type Culture Collection (ATCC) strains P.aeruginosa (ATCC 27853), E. coli (ATCC 25922) were used as control strains for the culture and antimicrobial susceptibility testing.

\section{Statistical analysis}

After the collection of socio-demographic characteristics, associated factors and laboratory data using a structured questionnaire and laboratory report format, data were edited, cleaned, entered and analyzed using Statistical Package for Social Sciences (SPSS) version 22. Descriptive statistics, bivariate, and multivariate logistic regressions were performed. Bivariate logistic regression was employed to determine the association between the outcome variable and each independent variable. A binary logistic regression analysis was used to calculate the odds ratios (OR); crude odds ratio (COR) and adjusted odds ratio (AOR) to ascertain the degree of association between dependent and independent variables. All variables with $p$-value 0.20 in the bivariate logistic regression were transferred to multivariate logistic regression analysis to compute AOR. The regression model was first examined by the goodness of fit test using the HosmerLemeshow test to determine whether the model is adequately fitted to the study. In this study, multicollinearity among independent variables was detected using the standard errors for regression coefficients. Finally, variables with a p-value $<0.05$ with a corresponding $95 \%$ confidence interval (CI) were considered as statistically significant. 


\section{Operational definition}

Dirty materials: Dirty materials are soiled objects, unclean or impure.

Fingernail status: Status of the nail was either trimmed or untrimmed fingernails that serve as a vehicle for the transmission of food contaminating pathogens.

\section{Results}

\section{Socio-demographic characteristics}

A total of 301 food handlers were included in the study. Out of the total respondents, 265 (88.0\%) were females. The age of study participants ranged from 19 to 38 years (23.51 \pm 3.186 years). The majority of $241(80.1 \%)$ of the participants were between the ages of 21 and 30 years. One hundred fifty-six (51.8\%) were enrolled in secondary school with an average of 3.7 years of work experience in the cafeteria. Out of the total study participants, 37 (12.3\%) were certified for training in food handling and $265(88.0 \%)$ had previously undergone a medical checkup stool microscopy examination (Table 1).

\section{Prevalence and associated factors of Salmonella and Shigella carriers}

The prevalence of Salmonella and Shigella in this study was $22(7.3 \%)$ and $11(3.7 \%)$ respectively. In the current study, 13 independent variables were considered during the analysis of associated factors for Salmonella and Shigella carriers (Table 2). Accordingly in the multivariate analysis, hand washing after using the bathroom with water only $(\mathrm{AOR}=23.24,95 \% \mathrm{CI}: 2.13-254.17, P<0.01)$, no handwashing after using the bathroom $(\mathrm{AOR}=2.25$, 95\% CI: 5.11-77.34, $P<0.001)$, no hands washing after touching dirty materials $(\mathrm{AOR}=37.19$, 95\% CI: $5.66-$ 244.45, $\mathrm{P}<0.001$ ), no handwashing before food handling $(\mathrm{AOR}=33.1, \quad 95 \% \quad \mathrm{CI}: \quad 4.96-220.52, \quad \mathrm{P}<0.001)$, untrimmed fingernail $(\mathrm{AOR}=13.97,95 \% \mathrm{CI}: 3.40-57.36$, $\mathrm{P}<0.001$ ) were significant factors associated with Salmonella and Shigella carriers. However, no significant association was found between years of service, medical check-up, workers blowing their noses, touching food with bare hands, and certification in food preparation and handling, with Salmonella and Shigella colonization in this study (Table 3).

\section{Antimicrobial susceptibility patterns of Salmonella and Shigella isolates}

Antimicrobial susceptibility patterns were performed for 22 Salmonella and 11 Shigella isolates against 9 antimicrobial agents. All Salmonella and Shigella isolates were resistant to ampicillin. 22(100\%) Salmonella and $10(90.90 \%)$ Shigella isolates were resistant to gentamicin; and 21(95.50\% Salmonella and 11(100\%) Shigella isolates were resistant to amoxicillin. However, all Salmonella and Shigella isolates were susceptible to ciprofloxacin. Additionally, low resistance was observed for ceftriaxone, chloramphenicol and cotrimoxazole for Salmonella and Shigella. None of the isolates showed intermediate resistance (Table 4). Multidrug resistance in this study is defined as resistance to at least three classes of antimicrobial agents and out of the thirty-three isolates 12 (54.5\%) Salmonella and 10(90.90\%) Shigella species were multidrug- resistant isolates (Table 5).

Table 1 Socio-demographic characteristics of food handlers in Adigrat University student cafeteria, Tigrai, North Ethiopia March to August $2018(N=301)$

\begin{tabular}{|c|c|c|c|}
\hline Demographic characteristics & Characteristics & Frequency & Percent \\
\hline \multirow[t]{2}{*}{ Sex } & Male & 37 & 12.3 \\
\hline & Female & 264 & 87.7 \\
\hline \multirow[t]{2}{*}{ Age } & $\leq 20$ & 54 & 17.9 \\
\hline & $21-40$ & 247 & 80.1 \\
\hline \multirow[t]{2}{*}{ Marital status } & Single & 127 & 42.2 \\
\hline & Married & 174 & 57.8 \\
\hline \multirow[t]{2}{*}{ Educational level } & Secondary school & 187 & 62.12 \\
\hline & Higher than secondary school & 114 & 37.9 \\
\hline \multirow[t]{3}{*}{ Years of service } & $\leq 1$ & 36 & 12.0 \\
\hline & $1-2$ & 42 & 14.0 \\
\hline & $>2$ & 223 & 74.1 \\
\hline \multirow[t]{2}{*}{ Certified in food preparation and handling } & No & 264 & 87.7 \\
\hline & Yes & 37 & 12.3 \\
\hline \multirow[t]{2}{*}{ Medical check-up } & No & 36 & 12.0 \\
\hline & Yes & 265 & 88.0 \\
\hline
\end{tabular}


Table 2 Bivariate logistic regression analysis of factors associated with Salmonella and Shigella infections among food handler's working at Adigrat University Students' Cafeteria, Tigrai, Northern Ethiopia, March to August $2018(\mathrm{~N}=301)$

\begin{tabular}{|c|c|c|c|c|c|}
\hline \multirow[t]{2}{*}{ Variables } & & \multicolumn{2}{|c|}{$\begin{array}{l}\text { Growth of Salmonella and } \\
\text { Shigella }\end{array}$} & \multirow[t]{2}{*}{ COR $(95 \% \mathrm{Cl})$} & \multirow[t]{2}{*}{$\begin{array}{l}P \text { - } \\
\text { value }\end{array}$} \\
\hline & & $\begin{array}{l}\text { Positive } \\
\mathrm{N}(\%)\end{array}$ & $\begin{array}{l}\text { Negative } \\
\mathrm{N}(\%)\end{array}$ & & \\
\hline \multirow[t]{2}{*}{ Sex } & Male & $1(2.7)$ & $36(97.3)$ & $0.22(0.03-1.58)$ & 0.20 \\
\hline & Female & $32(12.1)$ & $232(87.9)$ & 1 & \\
\hline \multirow[t]{2}{*}{ Age } & $\leq 20$ & $2(3.7)$ & $52(96.3)$ & $0.3(0.07-1.2)$ & 0.081 \\
\hline & $21-40$ & $31(12.55)$ & $216(87.45)$ & 1 & \\
\hline \multirow[t]{2}{*}{ Marital status } & Single & $16(12.6)$ & $111(87.4)$ & $1.29(.68-2.45)$ & 0.341 \\
\hline & Married & $17(9.78)$ & $157(90.23)$ & 1 & \\
\hline \multirow{5}{*}{$\begin{array}{l}\text { Educational status } \\
\text { Hand washing after using the bathroom }\end{array}$} & Lower than Secondary school & $16(8.56)$ & $171(91.44)$ & & 0.507 \\
\hline & Higher than secondary school & $17(14.9)$ & $97(85.1)$ & $1.74(0.92-3.31)$ & 0.862 \\
\hline & Yes with water and soap & $1(0.9)$ & $112(99.1)$ & 1 & \\
\hline & Yes only with water & $17(13.6)$ & $108(86.4)$ & $17.630(2.306-134.7)$ & 0.006 \\
\hline & No & $15(23.8)$ & $48(76.2)$ & $35.000(4.495-272.49)$ & 0.001 \\
\hline \multirow[t]{3}{*}{ Hand washing after touching dirty materials } & Yes with water and soap & $5(3.4)$ & $141(96.6)$ & 1 & \\
\hline & Yes only with water & $14(11.0)$ & $113(89.0)$ & $3.494(1.222-9.991)$ & 0.020 \\
\hline & No & $14(50.0)$ & $14(50.0)$ & $28.200(8.845-89.906)$ & 0.001 \\
\hline \multirow[t]{3}{*}{ Handwashing before food handling } & Yes with water and soap & $2(1.8)$ & $112(98.2)$ & 1 & \\
\hline & Yes only with water & $13(9.2)$ & $129(90.8)$ & $5.643(1.247-25.548)$ & 0.025 \\
\hline & No & $18(40.0)$ & $27(60.0)$ & $37.333(8.164-170.714)$ & 0.001 \\
\hline \multirow[t]{2}{*}{ Fingernail status } & Trimmed & $4(2.2)$ & $174(97.8)$ & 1 & \\
\hline & Untrimmed & $29(23.6)$ & $94(76.4)$ & $10.490(3.780-29.09)$ & 0.001 \\
\hline \multirow[t]{3}{*}{ After blowing nose } & Yes with water and soap & $7(8.0)$ & $81(92.0)$ & 1 & \\
\hline & Yes only with water & $11(11.7)$ & $83(88.3)$ & $0.919(0.401-2.107)$ & 0.842 \\
\hline & No & $15(12.6)$ & $104(87.4)$ & $0.599(0.233-1.538)$ & 0.287 \\
\hline \multirow[t]{2}{*}{ Touch food with bare hands } & No & $16(14.0)$ & $98(86.0)$ & 1 & \\
\hline & Yes & $17(9.1)$ & $170(90.9)$ & $1.597(0.772-3.302)$ & 0.207 \\
\hline \multirow[t]{3}{*}{ Years of service } & $\leq 1$ & $9(25.0)$ & $27(75.0)$ & $3.72(1.76-78.50)$ & 0.001 \\
\hline & $1-2$ & $9(21.4)$ & $33(78.6)$ & $0.818(0.285-2.349)$ & 0.709 \\
\hline & $>2$ & $15(6.7)$ & $208(93.3)$ & 1 & \\
\hline \multirow[t]{2}{*}{ Certified in food preparation and handling } & No & $29(11.5)$ & $224(88.5)$ & 1 & \\
\hline & Yes & $4(8.3)$ & $44(91.7)$ & $0.702(0.235-2.097)$ & 0.527 \\
\hline \multirow[t]{2}{*}{ Medical check-up } & No & $10(18.5)$ & $44(81.5)$ & 1 & \\
\hline & Yes & $23(9.3)$ & $224(90.7)$ & $1.99(1.01-3.93)$ & 0.04 \\
\hline
\end{tabular}

Key: ${ }^{\text {a }}\left(\mathrm{COR}=\right.$ Crude odds ratio); ${ }^{\mathrm{b}}(\mathrm{Cl}=$ Confidence interval); 1 (referent)

\section{Discussion}

In this study, the prevalence of Salmonella among food handlers was 22 (7.3\%). This was similar to studies carried out in Southern Ethiopia, Arba Minch University (6.9\%) [14], and Nigeria, Abeokuta (5.5\%) [21]. However, it was higher than the studies reported from Ethiopia, Addis Ababa (3.5\%) [22], Bahir Dar (1.6\%) [23], and Gondar (3.1\%) [24]. On the other hand, our result was lower than the studies reported from Ethiopia, Addis
Ababa (10.5\%) [25], and Nigeria (42.3\%) [26]. The variation might be attributed to poor personal hygiene and environmental sanitation differences among the study areas.

The prevalence of Shigella (3.7\%) in our study is consistent with studies done in Arba Minch University, Southern Ethiopia (3\%) [14]; Addis Ababa, Ethiopia (4.5\%) [25], and Gondar Ethiopia (3.1\%) [26]. However, our finding was lower than a study conducted in Nigeria 
Table 3 Multivariate logistic regression analysis of factors associated with Salmonella and Shigella isolates among food handler's working at Adigrat University Students' Cafeteria, Tigrai, Northern Ethiopia, March to August 2018 (N=301)

\begin{tabular}{|c|c|c|c|c|c|c|}
\hline \multirow[t]{2}{*}{ Variables } & \multicolumn{2}{|c|}{ Growth of Salmonella and Shigella } & \multirow[t]{2}{*}{$\operatorname{COR}^{a}\left(95 \% \mathrm{Cl}^{b}\right)$} & \multirow{2}{*}{$\begin{array}{l}\text { P- } \\
\text { value }\end{array}$} & \multirow[t]{2}{*}{ AOR $^{c}(95 \% \mathrm{Cl})$} & \multirow{2}{*}{$\begin{array}{l}\text { P- } \\
\text { value }\end{array}$} \\
\hline & $\begin{array}{l}\text { Positive } \\
\mathrm{N}(\%)\end{array}$ & $\begin{array}{l}\text { Negative } \\
\mathrm{N}(\%)\end{array}$ & & & & \\
\hline \multicolumn{7}{|c|}{ Hand washing using after using the bathroom } \\
\hline Yes with water and soap & $1(0.9)$ & $112(99.1)$ & 1 & & 1 & \\
\hline Yes only with water & $17(13.6)$ & $108(86.4)$ & $17.630(2.306,134.7)$ & 0.006 & $23.239(2.125-254.17)$ & $0.010^{*}$ \\
\hline No & $15(23.8)$ & $48(76.2)$ & $35.000(4.495,272.49)$ & 0.001 & $62.917(5.11-77.34)$ & $0.001^{*}$ \\
\hline \multicolumn{7}{|c|}{ Hand washing after touching dirty materials } \\
\hline Yes with water and soap & $5(3.4)$ & $141(96.6)$ & 1 & & 1 & \\
\hline Yes only with water & $14(11.0)$ & $113(89.0)$ & $3.494(1.222,9.991)$ & 0.020 & $1.089(0.187-6.345)$ & 0.924 \\
\hline No & $14(50.0)$ & $14(50.0)$ & $28.200(8.845,89.906)$ & 0.000 & $37.189(5.658-244.45)$ & $0.001^{*}$ \\
\hline \multicolumn{7}{|c|}{ Hand washing before food handling } \\
\hline Yes with water and soap & $2(1.8)$ & $112(98.2)$ & 1 & & 1 & \\
\hline Yes only with water & $13(9.2)$ & $129(90.8)$ & $5.643(1.247,25.548)$ & 0.025 & 5.972 (0.899-39.677) & 0.064 \\
\hline No & $18(40.0)$ & $27(60.0)$ & $37.333(8.164,170.714)$ & 0.000 & 33.065 (4.958-220.52) & $0.001^{*}$ \\
\hline \multicolumn{7}{|l|}{ Finger nail status } \\
\hline Trimmed & $4(2.2)$ & $174(97.8)$ & 1 & & 1 & \\
\hline Untrimmed & $29(23.6)$ & $94(76.4)$ & $10.490(3.780,29.09)$ & 0.000 & $13.973(3.404-57.362)$ & $0.001^{*}$ \\
\hline
\end{tabular}

(15.5\%) [27]. These might be due to the differences in inconsistent training on food preparation and handling and hygiene practices of the food handlers.

In the present study, not practicing handwashing after using the bathroom among food handlers was significantly associated with Salmonella and Shigella carriers. Food handlers who hadn't washed their hands after using the bathroom were more likely to be colonized with Salmonella and Shigella compared to those who washed with water and soap after using the bathroom. This finding was similar to a study conducted in Mekelle, Ethiopia [28], Gondar, Ethiopia [29], and Bahir Dar, Ethiopia [30]. The acquisition of Salmonella and Shigella is due to poor sanitary conditions, poor toilet facilities, and scarcity of availability of facilities used for handwashing practice. The majority of food handlers of the university reported that they washed their hands with only water and some of them did not wash their hands at all after using the bathroom.

Our findings also revealed that there is a statistically significant difference in handwashing after touching dirty materials among food handlers with Salmonella and Shigella carriers. Food handlers who did not wash their hands after touching dirty materials are twentyeight fold more likely to be colonized with Salmonella and Shigella than those who washed with water and soap after touching dirty materials. This finding is consistent with a study conducted in Ethiopia, Bahir Dar [23]. This might be due to the absence of handwashing facilities within proximity of the food handlers' workplace.

Our study showed that food handlers who washed their hand with soap and water before touching food were less likely to be colonized with Salmonella and Shigella than food handlers who did not wash their hand

Table 4 Antimicrobial susceptibility patterns of Salmonella and Shigella isolated from food handlers Of Adigrat University Students' Cafeteria, Tigrai, Northern Ethiopia, March to August 2018 ( $N=33$ )

\begin{tabular}{|c|c|c|c|c|c|c|c|c|c|c|}
\hline \multirow[t]{2}{*}{ Isolates(n) } & \multirow{2}{*}{$\begin{array}{l}\text { Sensitivity } \\
\text { pattern } \\
\mathrm{n}(\%)\end{array}$} & \multicolumn{9}{|c|}{ Antimicrobial agents $\mathrm{N}(\%)$} \\
\hline & & GM & AML & AMP & CIP & CLR & TS & AMC & $\mathrm{CHL}$ & CRO \\
\hline \multirow[t]{2}{*}{ Salmonella n(22) } & $S$ & $22(100)$ & $1(4.5)$ & $0(0.00)$ & $22(100)$ & $18(81.8)$ & $20(90.9)$ & $13(59.1)$ & $22(100)$ & $22(100)$ \\
\hline & $\mathrm{R}$ & $0(0.00)$ & $21(95.5)$ & $22(100)$ & $(0.00)$ & $4(18.2)$ & $2(9.1)$ & $9(40.9)$ & $0(0.00)$ & $0(0.00)$ \\
\hline \multirow[t]{2}{*}{ Shigella n (11) } & $S$ & $10(90.9)$ & $0(0.00)$ & $0(0.00)$ & $11(100)$ & $2(18.2)$ & $10(90.9)$ & $6(54.5)$ & $9(81.2)$ & $10(90.9)$ \\
\hline & $\mathrm{R}$ & $1(9.1)$ & $11(100)$ & $11(100)$ & $0(0.00)$ & $9(81.2)$ & $1(9.1)$ & $5(45.5)$ & $2(18.2)$ & $1(9.1)$ \\
\hline
\end{tabular}

Key: $\mathrm{S}=$ Sensitive $\mathrm{R}=$ Resistant, GM Gentamicin, AML Amoxicillin, AMP Ampicillin, CIP=Ciprofloxacin, CLR Clarithromycin, TS Cotrimoxazole, AMC Amoxicillinclavulanic acid CHL Chloramphenicol, CRO Ceftriaxone 
Table 5 Multidrug-resistant of Salmonella and Shigella isolated from food handler's working at Adigrat University Students' Cafeteria, Tigrai, Northern Ethiopia, March to August 2018 N = 33

\begin{tabular}{llll}
\hline & Antimicrobials & \multicolumn{2}{l}{ Resistant isolates no. (\%) } \\
\cline { 3 - 4 } & & Salmonella & Shigella \\
\hline For three & $\mathrm{AML}, \mathrm{AMP}, \mathrm{CLR}$ & $2(16.67)$ & $4(40)$ \\
& $\mathrm{AML}, \mathrm{AMP}, \mathrm{CHL}$ & $7(58.34)$ & - \\
& $\mathrm{AML}, \mathrm{CLR}, \mathrm{AMC}$ & $1(8.33)$ & - \\
& $\mathrm{AMP}, \mathrm{CLR}, \mathrm{AMC}$ & $1(8.33)$ & - \\
FOR FOUR & $\mathrm{AML}, \mathrm{AMP}, \mathrm{CLR}, \mathrm{AMC}$ & $1(8.33)$ & $3(30)$ \\
FOR FIVE & $\mathrm{AML}, \mathrm{AMP}, \mathrm{CLR}, \mathrm{AMC}, \mathrm{CHL}$ & - & $1(10)$ \\
FOR SIX & $\mathrm{GM}, \mathrm{AML}, \mathrm{AMP}, \mathrm{CLR}, \mathrm{TS}, \mathrm{AMC}$ & - & $1(10)$ \\
& & $12(100)$ & $10(100)$ \\
\hline
\end{tabular}

Key: GM Gentamicin, AML Amoxicillin, AMP Ampicillin, CIP=Ciprofloxacin, CLR Clarithromycin, TS Cotrimoxazole, AMC Amoxicillin-clavulanic acid CHL Chloramphenicol, CRO, Ceftriaxone MDR multidrug resistant; MDR definition for Salmonella and Shigella percent is computed from total number of Salmonella and Shigella

with soap and water before food preparation. This is in line with the finding of a similar study reported fromYebu Town Ethiopia [31]. In this study, the majority offood handlers practiced handwashing before handling food. However, a very large proportion (47.1\%) washed their hands only with water. There are food handlers who apply some hygiene practice, though many of them do not use soap nor do they appreciate or understand the need for handwashing [32].

Furthermore, in this finding, untrimmed fingernails were significantly associated with Salmonella and Shigella colonization among food handlers. This study is similar to studies conducted in-Yebu Town, Ethiopia [31], and Arba Minch, Ethiopia [14]. This result might be due to the lifestyle of food handlers. Examination of fingernail contents of food handlers for Salmonella or Shigella is one way of indicating a source of possible food contamination [31]. However, the current study did not assess the Salmonella and Shigella carriage of fingernail contents.

Salmonella and Shigella carriers who are preparing and handling food daily can act assources of infection to the university community via the food chain. Therefore, regular training, medical check-up programs and accessibility of personal hygiene guidelines with intensive health education could be important to prevent and control the carriage.

Antimicrobial susceptibility pattern data showed that ciprofloxacin, ceftriaxone, gentamicin, chloramphenicol, and cotrimoxazole were effective against the Shigella isolates. Our finding was comparable with studies reported from Ethiopia, Haramaya University on ceftriaxone (16.7\%) [33], Jimma on gentamicin (1.3\%) [34], and Harar on gentamicin (3.6\%) [35]. Whereas our result showed lower resistance patterns compared to the studies conducted in Ethiopia, Addis Ababa on gentamicin (75.6\%) [36], and Gondar on ciprofloxacin (8.9\%) and cotrimoxazole $(73.4 \%)[37,38]$. This increase of resistance from those reports indicates that there are differences in the geographical area, study period and study design. Increased resistance was observed in our finding which is in line with a study reported from Harar on ampicillin (100\%) [35], and Arba Minch on amoxicillin (100\%) [14].

In the current study, isolates of Salmonella species were sensitive to gentamicin, ciprofloxacin, chloramphenicol, ceftriaxone, cotrimoxazole, and clarithromycin. This is consistent with reports from Gondar University, Ethiopia [24, 25, 38]. Increased resistance was observed in our findings for amoxicillin-clavulanic, amoxicillin, and ampicillin which were supported by studies reported from Ethiopia in Arba Minch, Jimma, and Bahir Dar [12, $14,23,35]$. This might be due to misuse or inappropriate use of antibiotics and the use of clinical diagnosis for treatment by physicians may lead to the emergence of drug-resistant bacterial strains and replacement of sensitive strains by resistant strains.

The prevalence of multidrug resistance towards Salmonella and Shigella were observed. Out of all the isolates, 54.54\% Salmonella and 90.9\% Shigella species were resistant to at least three antimicrobials. One isolate of Shigella was resistant to six classes of antimicrobial agents. This study is supported by a study conducted in Ethiopia in Butajira [25], Addis Ababa [22], Haramaya University [33], and Gondar [24]. This increased multidrug resistance might be due to genetic variation by mutations, irrational use of antimicrobials, and less hygienic practice of the food handlers. Salmonella and Shigella species are becoming resistant to most antimicrobials, indicating that there might be easy availability, irrational use of common antimicrobials from different governmental and private pharmacies.

\section{Limitation}

Fingernail content examination could not be identified. This may be supportive to know whether the contamination is due to poor fingernail hygiene or poor food handling practices. Despite this limitation, the methods used to isolate and characterize the antimicrobial susceptibility pattern of Salmonella and Shigella spp. are comprehensive. In the current study, because of the selfreported nature of the study, recall bias was a limitation but it is not reflected in the findings. We also do not know what biases have the greatest impact on selfreports. In addition to that, even though this study used a random sampling technique to select study participants, it was facility-based. The Hosmer-Lemeshow test is used for overall calibration error but not used for a 
particular lack of fitness, so it does not properly take overfitting into account. Therefore generalizability might be hardly achieved. Additionally, since there is variation in seasons, geography, and in the definition of antimicrobial resistance guidelines among different studies and across regions we couldn't infer the external validity.

\section{Conclusion}

The overall prevalence of Salmonella and Shigella in the study area was found to be 7.3 and $3.7 \%$ respectively. The Salmonella and Shigella carriage was significantly associated with not washing hands after touching dirty materials, not washing hands after using the bathroom, and untrimmed fingernails. No resistance against chloramphenicol, ceftriaxone, and ciprofloxacin was identified. The majority of Salmonella and Shigella were multidrug-resistant. To improve food handling safety within the university, regular medical checkups, increased handwashing, and environmental sanitation should be practiced. Consistent training on food preparation and handling for the food handlers of Adigrat University is very important to prevent the risk of infection for the university community having close contact with those carriers. Additionally, this study suggested that physicians should prescribe based on the laboratory result. Drug dispensing by different governmental and private pharmacies should be according to the prescription of the physicians.

\section{Abbreviations}

ATCC: American Type Culture Collection; Cl: confidence interval; CLSI: Clinical and Laboratory Standards Institute; MDR: Multi-drug resistant Multi-Drug Resistant; SOPs: Standard Operating Procedures; USA: United States of America; WHO: World health organization

\section{Acknowledgments}

The authors gratefully acknowledge the food handlers of Adigrat University for their participation in the study. We also wish to extend our deep appreciation to Adigrat University, College of Medicine and Health Sciences for providing us with the opportunity to do this research and allowing the finance.

\section{Authors' contributions}

$\mathrm{HL}$ designed the study, collection, analysis, and interpretation of data, and drafted the manuscript. TK, AG, BB, and BF designed the study, supervised data collection both on-field and in the laboratory, and prepared the manuscript. ST, GG, HN, and GA read and approved the final manuscript.

\section{Funding}

Not applicable.

\section{Availability of data and materials}

All data collected and analyzed during this study were included in the manuscript. But if the full paper is needed, it will be shared upon request by the editor from the corresponding author.

\section{Ethics approval and consent to participate}

The study was approved by the College of medicine and health sciences Research ethical review committee of Adigrat University, Ethiopia (Consent Ref Number AGU/CMHS/044/2018 approval dated 07/04/2018 Official letter was obtained from Adigrat University (Consent Ref Number AGU/CMHS/ RCSH/19/2018 approval dated 25/04/2018. Written informed consent was sought from each study participant before sample collection and maintained throughout the study. All participants were given code numbers to keep their identity confidential.

\section{Consent for publication}

Not applicable.

\section{Competing interests}

The authors' declared that there were no competing interests.

\section{Author details}

${ }^{1}$ Department of Medical Laboratory, College of Medicine and Health Science, Adigrat University, Adigrat, Ethiopia. '2Department of public health, College of Medicine and Health Science, Adigrat University, Adigrat, Ethiopia.

${ }^{3}$ Department of Medical Laboratory, College of Medicine and Health Science, Bahr dar University, Bahr dar, Ethiopia.

Received: 4 February 2020 Accepted: 2 September 2020

Published online: 11 September 2020

\section{References}

1. Centers for Disease Control and Prevention (CDC). Surveillance for foodborne disease outbreaks-United States, 2008. MMWR 2010; 59(31):12771280.

2. World Health Organization (WHO). (2007). Fact Sheet Number 237: Food safety and foodborne illness. Geneva, Switzerland: World Health Organization. Available at http://www. Who.int/media centre/factsheets/ fs237/en/. accessed June 26, 2017.

3. B. Coburn, G. A. Grassl, and B. B. Finlay, "Salmonella, the host and disease: a brief review," Immunology and Cell Biology 2007;85;2:112-118.

4. Majowicz SE, Musto J, Scallan E, Angulo FJ, O'Brien SJ, Jones TF. The global burden of nontyphoidal Salmonella gastroenteritis. Clin Infect Dis. 2010;50: 882-9.

5. Centers for Disease Control and Prevention. Surveillance for foodborne disease outbreaks the United States. MMWR. Morb Mortal Wkly Rep 2011. 2008;60(35):1197-202.

6. World Health Organization (WHO) laboratory identification and antimicrobial susceptibility testing of bacterial pathogens of public health concern in the developing world Geneva, Switzerland: World Health Organization; 2003.

7. Smith SI, Fowora M. A, Goodluck H.A, Nwaokorie F.O, Aboaba O.O, Opere B. Molecular typing of Salmonella spp isolated from food handlers and animals in Nigeria Int J Mol Epidemiol Genet 2011; 2(1):73-77.

8. Feasey NA, Dougan G, Kingsley RA, Heyderman RS, Gordona MA. Invasive non-typhoidal salmonella disease: an emerging and neglected tropical disease in Africa. Lancet. 2012:379(9835):2489-99.

9. Pala K, Ozakin C, Akis N, Sinirtas M, Gediko S, Aytekin H: Asymptomatic carriage of bacteria in food workers in Nilüfer district, Bursa, TurkeyTurk J Med Sci 2010; 40(1):133-139.

10. Khurana S, Taneja N, Thapar R, Sharma M, Malla N: Intestinal bacterial and parasitic infections among food handlers in a tertiary care hospital of North India. Trop Gastroenterol 2008; 29:207-209.

11. Ao TT, Feasey NA, Gordon MA, Keddy KH, Angulo FJ, Crump JA. Global Burden of Invasive Nontyphoidal Salmonella Disease Emerg. Infect Dis 2015 21(6):441-449 DOl: https://doi.org/10.3201/eid2106.140999.

12. Beyene G, Tasew H. Prevalence of intestinal parasite, Shigella and Salmonella species among diarrheal children in Jimma health center, Jimma southwest Ethiopia: a cross-sectional study. Ann Clin Microbiol Antimicrob. 2014; 13:10. Published 2014 Feb 5. doi:https://doi.org/10.1186/1476-0711-1310

13. Mokhtari W, Nsaibia S, Majouri D, Ben Hassen A, Gharbi A, Aouni M. Detection and characterization of Shigella species isolated from food and human stool samples in Nabeul, Tunisia, by molecular methods and culture techniques. J Applied Microbiol. 2012;113:209-22. https://doi.org/10.1111/j. 1365-2672.2012.05324

14. Mama M, Getaneh A. Prevalence, antimicrobial susceptibility patterns and associated risk factors of Shigella and Salmonella among food handlers in Arba Minch University, South Ethiopia. BMC Infect Dis. 2016; 16:686.

15. Scallan E, Hoekstra RM, Angulo FJ, Tauxe RV, Widdowson MA, Roy SL, Jones IL, Griffin PM. Foodborne illness acquired in the United States-major pathogens. Emerg Infect Dis. 2011;17(1):7-15. 
16. Bonkoungou IJO, Haukka K, Österblad M, Hakanen AJ, Traoré AS, Barro N, et al. Bacterial and viral etiology of childhood diarrhoea in Ouagadougou, Burkina Faso. BMC Pediat. 2013;13(36):1-6.

17. Afeworki G, Lirneneh Y. Multiple drug resistance within Shigella serogroups. Ethiop Med J. 1980;18:7-11.

18. Roma B, Worku S. T/Mariam S, Langeland N. antimicrobial susceptibility pattern of Shigella isolates in Awassa. Ethiop J of Health Dev. 2000;14:14954

19. Beyene G, Asrat D, Mengistu Y, Aseffa A, Wain J. Typhoid fever in Ethiopia. J Infect Developing Countries. 2008;2:448-53.

20. Clinical and Laboratory Standards Institute (CLSI): Performance standards for antimicrobial susceptibility testing; Twenty-sixth Informational Supplement. Wayne PA 19087 USA 2016; 36(1)

21. Mobolaji OA, Olubunmi OF. Assessment of the hygienic practices and the incidence of enteric bacteria in food handlers in small businesses in an urban area in Abeokuta. Int J Microbiol Res. 2014;5(3):41-9.

22. Aklilu A, Kahase D, Dessalegn M, Tarekegn N, Gebremichael S, Zenebe S, et al. Prevalence of intestinal parasites, salmonella and shigella among apparently health food handlers of Addis Ababa university student's cafeteria, Addis Ababa, Ethiopia. BMC Res Notes. 2015;8(17):1-6.

23. Abera B, Biadegelgen F, Bezabih B. Prevalence of Salmonella typhi and intestinal parasites among food handlers in Bahir Dar town, Northwest Ethiopia. Ethiop J Health Dev. 2010;24(1):46-50.

24. Garedew-Kifelew L, Wondafrash N, Feleke A. Identification of drug-resistant Salmonella from food handlers at the University of Gondar, Ethiopia. BMC Res Notes. 2014;7(1):545.

25. Mengistu G, Mulugeta G, Lema T, Aseffa A. Prevalence and antimicrobial susceptibility patterns of Salmonella serovars and Shigella species. J Microb Biochem Technol. 2014;S2:006. https://doi.org/10.4172/1948-5948.S2-006.

26. Ifeadike C, Ironkwe O, Adogu P, Nnebue C, Emelumadu O, Nwabueze S, Ubajaka C. Prevalence and pattern of bacteria and intestinal parasites among food handlers in the Federal Capital Territory of Nigeria. Niger Med J. 2012;53(3):166

27. Andargie G, Kassu A, Moges F, Tiruneh M, Huruy K. Prevalence of bacteria and intestinal parasites among food handlers in Gondar town, Northwest Ethiopia. J Health Popul Nutri. 2008;26(4):451-5.

28. Nigusse D and Kumie A. Food hygiene practices and prevalence of intestinal parasites among food handlers working in Mekelle university student's cafeteria, Mekelle. Global Adv Res J of Soc Sci (GARJSS),2012;1(4): 065-071.

29. Dagnew M, Tiruneh M, Moges F, Gizachew M. Bacterial Profile and Antimicrobial Susceptibility Pattern among Food Handlers at Gondar University Cafeteria, Northwest Ethiopia. J Infect Dis Ther.2013;1: 105. doi: https://doi.org/10.4172/2332- 0877.1000105.

30. Abera B, Yitayew G, Amare H. Salmonella serotype Typhi, Shigella, and intestinal parasites among food handlers at Bahir Dar University, Ethiopia. J Infect Dev Ctries. 2016;10(2):121-6.

31. Tefera T, Mebrie G. Prevalence and Predictors of Intestinal Parasites among Food Handlers in Yebu Town, Southwest Ethiopia. PLoS ONE.2014; 9 (10): e110621. doi:https://doi.org/10.1371/journal.pone.0110621.

32. Zain MM, Naing NN. Sociodemographic characteristics of food handlers and their knowledge, attitude and practice towards food sanitation: a preliminary report. Southeast Asian J Trop Med Public Health. 2002;33(2): 410-7.

33. Marami D, Hailu K, and Tolera M. Prevalence and antimicrobial susceptibility pattern of Salmonella and Shigella species among asymptomatic food handlers working in Haramaya University cafeterias, Eastern Ethiopia. BMC Res Notes.2018; 11:74

34. Mache A. Salmonella serogroups and their antibiotic resistance patterns isolated from diarrhoeal stools of pediatric out-patients in Jimma Hospital and Jimma Health Center, South West Ethiopia. Ethiop J Health Sci2002; 37: 37-45.

35. Reda AA, Seyoum B, Yimam J, Andualem G, Fiseha S, Vandeweerd J-M Antibiotic susceptibility patterns of Salmonella and Shigella isolates in Harar, Eastern, Ethiopia J Infect Dis Immun 2011; 3: 134-139.

36. Asrat D. Shigella and Salmonella serogroups and their antibiotic susceptibility patterns in Ethiopia. East Mediterr Heal J. 2008;14:760-7.

37. Yismaw $O$, Negeri C, Kassu A. A five-year antimicrobial resistance pattern observed in Shigella species isolated from stool samples in Gondar University hospital, Northwest Ethiopia. Ethiop J Heal Dev. 2006;20:194-8.
38. Tiruneh M Serodiversity and antimicrobial resistance pattern of Shigella isolates at Gondar University teaching hospital, Northwest Ethiopia Jpn J Infect Dis 2009; 62(2):93-97.

\section{Publisher's Note}

Springer Nature remains neutral with regard to jurisdictional claims in published maps and institutional affiliations.
Ready to submit your research? Choose BMC and benefit from:

- fast, convenient online submission

- thorough peer review by experienced researchers in your field

- rapid publication on acceptance

- support for research data, including large and complex data types

- gold Open Access which fosters wider collaboration and increased citations

- maximum visibility for your research: over $100 \mathrm{M}$ website views per year

At $\mathrm{BMC}$, research is always in progress.

Learn more biomedcentral.com/submissions 